\title{
MANGANESE DEFICIENCY IN PEACH TREES: PROGNOSIS AND FRUIT QUALITY
}

Val, J., Monge, E., Montañés, L., and Sanz, M.

Estación Experimental Aula Dei (CSIC). Apdo. 202. 50080 Zaragoza (SPAIN).

\section{ABSTRACT}

In previous studies was pointed out that it may be possible to detect subclinical manganese deficiencies in the field before visual symptoms have developed. In this work, by in situ fluorescence measurements, we demonstrate that it is possible to predict, at the beginning of the season, which trees will develop manganese deficiency several months later. Fo/Fm ratio of young manganese deficient leaves without visible symptoms was higher than the measured in the equivalent control leaves. More than $80 \%$ of concordance, between the initial measurements and the symptoms lately developed was reached. This facts made us to believe that it could be possible to predict manganese deficiency just when the first leaves appeared and therefore apply effective correcting measures to prevent manganese deficiency in peach trees. Economical repercussion of manganese deficiency, in terms of yield and fruit characteristics, are also discussed.

Index Key KeyWords: Manganese deficiency, Peach, prognosys, fluorescence, fruit quality

\section{INTRODUCTION}

Manganese deficiency is a recurring problem in a broad number of plant species. Examples can be given for soybean in hydroponics (Pérez et al. 1993) or grown on high pH soils (Graham et al., 1995);; Norway spruce (Polle and Chakrabarti 1994), barley (Huang-ChunYuan et al., 1996), and many others including wheat, triticale, palm, chickpea, etc. Yields of crops, pastures and trees are affected adversely by either deficiencies or toxicities of manganese. Concomitantly, symptoms of the disorder usually but not always appear on leaves, roots or fruits (Lindsay et al., 1988). Typical symptoms of Mn deficiency are interveinal chlorosis, dark brown spots on leaves and premature senescence of leaves. Manganese deficiency results in shortened internodes, increased leaf abscission and decreased lateral root formation. This micronutrient plays a key role in photosynthesis, respiration, nitrogen metabolism and nodulation, synthesis of lipids, lignin, phenols and hormones (auxin balance).

In general terms, diagnosis of Mn deficiency by leaf analysis can be retrospective if the time between sample collection and analytical interpretation is prolonged (Hannam and Ohki, 1988) or if the sampling time is too late (when suspicious symptoms are already evident). Chlorophyll fluorescence has been used as a measure of photosynthetic dysfunction to permit early diagnosis of Mn deficiency. Enhanced fluorescence at low Mn concentrations in leaves reflects a functional association between leaf $\mathrm{Mn}$ and electron transport from water to photosystem II (Kriedeman et al., 1988). The ratio between variable fluorescence (Fv) and basal fluorescence (Fo) can provide a good indication of the physiological state of the plant under Mn-deficiency (Val et al., 1993, 1995). Upon accomplishing fluorescence measures in leaves of Mn-deficient wheat 
(Kriedeman et al., 1985) and peach (Val et al., 1995), it was found an strongly increased Fo and a decreased Fv, together with a clear loss of capacity to evolve $\mathrm{O}_{2}$. In this work, we attempt to demonstrate that the ratio between basal and maximal fluorescence measured in young leaves from manganese deficient peach trees, without visible symptoms, is higher than that of healthy leaves. Therefore, it could be possible to predict manganese deficiency just when the first leaves appeared.

\section{MATERIALS AND METHODS}

In situ non-destructive fluorescence measurements were done at the beginning of April on young leaves from a 12-year-old peach tree orchard (Prunus persica L. Batsch cv. Baby Gold 7) located in El Temple (Huesca, Spain). Both control and manganese deficient leaves were visually recognized to assure that potentially manganese deficient leaves did not show yet any visual symptoms.

The experiments were carried out 1995 on 38 trees chosen at random. Three or four shoots per tree were marked with a ribbon that was numbered for a further identification. An area of the first fully developed leaf of each shoot was dark adapted for 20 minutes by closing the small windows of the clip which holds the fluorescence probe. Once dark-adapted the leaves were measured by a portable Hansatech fluorometer PEA (photosynthesis efficiency analyzer). This equipment provides some parameters of the kinetics of fluorescence: Fo (all reaction centers open); Fm where the reactions centers are closed, and the variable fluorescence, $\mathrm{Fv}$, calculated by the difference between Fm and Fo. The measurements were replicated two more times in different parts of the same leaf.

In order to make a detailed rapport of the studied trees along the season, the fluorescence-measured leaves were identified and visually diagnosed for manganese deficiency at harvesting.

At harvest time the fruits from the marked shoots were collected, weighted and measured. They were classified depending on the severity of the deficiency affecting the shoots. The fruit prices per $\mathrm{kg}$ of as a function of their size were collected from the local newspapers.

\section{RESULTS AND DISCUSSION}

In a previous work Val et al (1993) found that by poisoning with DCMU a suspension of Mn deficient soybean leaves it was possible to isolate the contribution of photosystem II to the total yield of fluorescence through the blockage of $\mathrm{Q}_{\mathrm{B}}$. Based on this fact, it could be assessed that Mn-deficient soybean leaves have a diminished number of functional photosystem II (PS2) particles. Furthermore, the value of photochemical quenching $\mathrm{qQ}=0$ indicates that all the energy collected by the antenna is driven to a small number of reaction centers. These are the reasons for the Fv/Fm diminution induced by manganese deficiency that results from a relatively lower concentration of active PS2 reaction centers compared with a high number of light harvesting structures. Therefore, the energy collected by the antenna cannot be driven to open PS2 traps, and then one part of this extra energy has to be dissipated in the form of LHC fluorescence. Thus, the antenna contribution to the total yield of fluorescence increases. The effects of 
manganese deficiency in the PS2 photochemistry are translated in an increase in the contribution of the LHC to the fluorescence emission (Fo) at the same time as the yield of the PS2 (Fv) is reduced, both facts give as a result a decrease of the Fv/Fm ratio or, in other words, a decrease in the photosynthetic efficiency of the photosystem II.

Following these observations we continue the investigation on Mn deficiency on hydroponically cultured sugar beet plants. Once achieved the deficiency, it could be observed that the young leaves presented an homogeneous pigmentation indistinguishable from the young leaves grown under normal Mn concentrations. However, when fluorescence was measured, the already mentioned increase in Fo and diminution in the Fv/Fm value could be detected (data not shown).

The next step of this investigation consisted on the verification of these facts under field conditions (Val et al., 1995). Young leaves of Mn-deficient peach trees without visible symptoms of the deficiency were analyzed for leaf manganese concentration, photosynthetic pigments and fluorescence parameters. In this experiment, Fo and Fv/Fm values were correlated to the concentration of $\mathrm{Mn}$ in young leaves, but the leaf chlorophyll contents were similar irrespective of their Mn concentration. In principle, we achieved the detection of Mn-deficiency when symptoms were subclinical.

The final control for prognosis purposes consisted on the verification of all these facts on the first fully developed peach leaves at the very beginning of the season. If in those conditions we could detect the deficiency of manganese and later confirm it, we can account on a powerful tool to correct in time the consequences of this disorder (Table 1).

For this study we introduced the use of Fo/Fm instead of the widely utilized Fv/Fm because this ratio explains the relative higher value of Fo (characteristic of $\mathrm{Mn}$ deficiency) compared with maximum yield of fluorescence (Fm). The Fo/Fm $>0.3$ taken as a reference for Mn-deficiency implies that more than $30 \%$ of the total fluorescence is due to the LHCII contribution, while for control plants no more that $20 \%$ fluorescence is attributable to Fo. As shown in Table 1 an $86 \%$ of coincidence between the initial prediction made at the beginning of April and the symptoms fully developed in July was reached. As a result of these findings we can stated that, it is possible an early diagnosis of Mn deficiency in peach trees by, in situ, measuring some chlorophyll fluorescence parameters.

Table 2 is a rapport about fruit quality demonstrated a relation between manganese deficiency and fruit fresh weight, size and market price. 
Table 1 Example of predictions for Mn deficiency (Fo/Fm>03) in branches of several peach trees. Each data correspond to the average of three measurements in different parts of the first fully developed leaf from a single shoot.

\begin{tabular}{|c|c|c|}
\hline $\begin{array}{l}\text { Prediction } \\
3 / 04 / 1996\end{array}$ & $\begin{array}{l}\text { Final Visual } \\
\text { Observation }\end{array}$ & Coincidences \\
\hline Control & Control & 1 \\
\hline Control & Control & 1 \\
\hline Control & Control & 1 \\
\hline$-\mathrm{Mn}$ & -Mn/Control & 1 \\
\hline$-\mathrm{Mn}$ & $-\mathrm{Mn}$ & 1 \\
\hline$-\mathrm{Mn}$ & -Mn/Control & 1 \\
\hline$-\mathrm{Mn}$ & $-\mathrm{Mn}$ & 1 \\
\hline$-\mathrm{Mn}$ & $-\mathrm{Mn}$ & 1 \\
\hline Control & Control & 1 \\
\hline Control & Control & 1 \\
\hline Control & Control & 1 \\
\hline Control & $-\mathrm{Mn} /-\mathrm{Fe}$ & 0 \\
\hline$-\mathrm{Mn}$ & Control & 0 \\
\hline$-\mathrm{Mn}$ & Control? & 0 \\
\hline$-\mathrm{Mn}$ & $-\mathrm{Mn}$ & 1 \\
\hline$-\mathrm{Mn}$ & -Mn/Control & 1 \\
\hline$-\mathrm{Mn}$ & $-\mathrm{Mn}$ & 1 \\
\hline$-\mathrm{Mn}$ & $-\mathrm{Mn}$ & 1 \\
\hline$-\mathrm{Mn}$ & $-\mathrm{Mn} /-\mathrm{Fe}$ & 1 \\
\hline$-\mathrm{Mn}$ & $-\mathrm{Mn}$ & 1 \\
\hline Control & Other Deficiency (nor -Mn) & 1 \\
\hline$-\mathrm{Mn}$ & Control/-Fe & 0 \\
\hline Control & $-\mathrm{Mn} /-\mathrm{Fe}$ & 0 \\
\hline$-\mathrm{Mn}$ & $-\mathrm{Mn}$ & 1 \\
\hline$-\mathrm{Mn}$ & -Mn/Control & 1 \\
\hline$-\mathrm{Mn}$ & -Mn/control & 1 \\
\hline$-\mathrm{Mn}$ & $-\mathrm{Mn}$ & 1 \\
\hline$-\mathrm{Mn}$ & $-\mathrm{Mn}$ & 1 \\
\hline Control & Control & 1 \\
\hline Control & Control & 1 \\
\hline Control & Control & 1 \\
\hline Control & Control & 1 \\
\hline Control & Control & 1 \\
\hline$-\mathrm{Mn}$ & -Mn and other disease & 1 \\
\hline$-\mathrm{Mn}$ & $-\mathrm{Mn}$ & 1 \\
\hline Control & Control & 1 \\
\hline \multirow[t]{2}{*}{ Control } & -Fe or control & 1 \\
\hline & \% Coincidence & 86 \\
\hline
\end{tabular}


Table 2 is a resume of the economical repercussions of manganese deficiency due to losses of decreased fruit quality. As can be seen in this table, the decrease in fruit size and weight depends on the severity of manganese deficiency that also induces the subsequent market fruit depreciation.

Table 2. Fruit characteristics as fresh weight and size (calibre) influence fruit market prices in relation to Mn deficiency

\section{Fresh weight}

Calibre

ECUS per kg*

Control

$\left.\begin{array}{llc}\mathbf{n}^{\mathbf{0}} \mathbf{1} & 333 & 91 \\ \mathbf{n}^{\mathbf{0}} \mathbf{2} & 325 & 87 \\ \mathbf{n}^{\mathbf{0}} \mathbf{3} & 330 & 88.5\end{array}\right\}$

Slight manganese deficiency

$\left.\begin{array}{llll}\mathbf{n}^{\mathbf{0}} \mathbf{1} & 245 & 80 & \\ \mathbf{n}^{\mathbf{0}} \mathbf{2} & 230 & 76 \\ \mathbf{n}^{\mathbf{0}} \mathbf{3} & 240 & 77\end{array}\right\} \quad 1.00$

\section{Severe manganese deficiency}

$\left.\left.\begin{array}{lll}\mathbf{n}^{\mathbf{0}} \mathbf{1} & 190 & 70 \\ \mathbf{n}^{\mathbf{0}} \mathbf{2} & 191 & 70 \\ \mathbf{n}^{\mathbf{0}} \mathbf{3} & 180 & 68\end{array}\right\} \quad\right\} \quad 0.25$

* Prices are the average of those reported by local newspapers in July-August of 1995

\section{CONCLUSION}

This work demonstrates the possibility for predicting manganese deficiency in peach trees early in the season. By using non-destructive fluorescence techniques manganese deficiency can be detected in peach tree individuals, thus there is no need of applying correcting measures to the whole orchard but only to the trees that need them. In this way, economic and environmental savings can be achieved.

\section{REFERENCES}

Edwards G and Walker D $1983 \mathrm{C}_{3}, \mathrm{C}_{4}$ : Mechanism, and cellular and environmental regulation of photosynthesis. Blackwell. Oxford

Graham M J, Nickell C D, and Hoeft R G (1995) Inheritance of tolerance to manganese deficiency in soybean. Crop-Science., 35, 1007-1010

Hannam R J, and Ohki K (1988) Detection of manganese deficiency and toxicity in plants. In: Manganese in soil and plants (Graham, R, D., Hannam, R, J., and Uren, N, C. eds). pp 243-259, Kluwer Academis Publishers, Dordrecht, The Netherlands.

Huang-ChunYuan, Webb M J, Graham R D, Huang C Y (1996) Pot size affects expression of Mn efficiency in barley. Plant and Soil. 178, 205-208 
Kriedemann P E and Anderson J E 1988 Growth and photosynthetic responses to manganese and copper deficiencies in wheat (Triticum aestivum) and barley grass (Hordeum glaucum). Aust. J. Plant Physiol. 15, 429-446

Kriedemann P E, Graham R D, and Wiskich J T (1985) Photosynthetic dysfunction and in vivo changes in chlorophyll a fluorescence from manganese-deficient wheat leaves. Aust. J. Agric. Res. 36: 157-169

Lindsay C, Campbell C, and Ross O N (1988) Physiological functions of manganese in plants. In: Manganese in soil and plants (Graham, R, D., Hannam, R, J., and Uren, N, C. eds). pp 139-154, Kluwer Academis Publishers, Dordrecht, The Netherlands.

Pérez C, Madero MP, Pequerul A, Val J, Monge E (1993) Specificity of manganese in some aspects of soybean (Glycine max L.) physiology. In: Optimization of the plant nutrition, (Fragoso, M.A.C., Van Beusichem, M.L. and Houwers, A., eds), pp 503507. Kluwer Acad. Publ. Dordrecht, The Netherlands.

Polle A, and Chakrabarti K (1994) Effects of manganese deficiency on soluble apoplastic peroxidase activities and lignin content in needles of Norway spruce (Picea abies). Tree-Physiology. 14, 1191-1200

Simpson DJ, and Robinson SP (1984) Freeze-fracture ultrastructure of the thylakoid membranes in chloroplasts from manganese deficient plants. Plant Physiol. 74, 735-741

Val J, Pérez C, Madero MP, Pequerul A, and Monge E (1993) Are manganese and iron deficiencies so similar? Fluorescence, a way of study. In: Optimization of the plant nutrition, (Fragoso, M.A.C., Van Beusichem, M.L. and Houwers, A., eds), pp 491496. Kluwer Acad. Publ. Dordrecht, The Netherlands.

Val J, Sanz M, Montanés L, and Monge E (1995) Application of chlorophyll fluorescence to study iron and manganese deficiencies in peach tree. (Refereed paper). Acta Horticulturae, 383, 201-210 